\title{
Violência, Ética e Direito: Implicações para o Reconhecimento da Violência Doméstica Contra Crianças
}

Violence, ethics and law: implication to the domestic violence against child recognition

Resumo: Os conceitos de violência desenvolvidos por Hannah Arendt e Marilena Chaú levam-nos a refletir a respeito da violência doméstica contra crianças, ampliando seu significado e possibilitando questionar determinados sentidos a ela atribuídos. A justificativa e a aplicação do Direito quanto ao que caracteriza um ato violento não conseguem abarcar situações como a violência doméstica e a violência institucional. Essas modalidades de violência parecem manter estreita ligação, pois ambas são colocadas à margem dos possíveis enquadramentos legais quanto aos danos que vêm causando às vítimas. Além disso,

Edinete Maria Rosa

Professora da Universidade Federal do Espírito Santo. Doutora em Psicologia Social pela Universidade de São Paulo (2003). Tese desenvolvida sob orientação da profa $D r^{a}$ Eda Terezinha de Oliveira Tassara.

\section{Eda Terezinha} de Oliveira Tassara

Professora e pesquisadora do Programa de PósGraduação em Psicologia Social da Universidade de São

Paulo. Doutora em Psicologia Experimental pela Universidade de são Paulo.

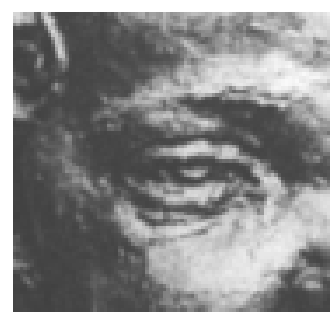
reificadas.

Palavras-Chave: Violência, Ética, direitos.

Abstract: The concepts of violence elaborated by $\mathrm{H}$. Arendt and $\mathrm{M}$. Chauí lead us to reflect on the wider significance of domestic violence against children and question some interpretations about it. The interpretations and the application of the penal code as to what characterises a violent act does not successfully cover situations of domestic and institutional violence. These forms of violence are closely linked, as both are outside the contingencies of the legal framework in terms of injuries caused to the victims. Moreover, both are necessary to maintain the status quo, since they reproduce interpersonal relations based on possession.

Key Words: Violence, Ethics, rights.

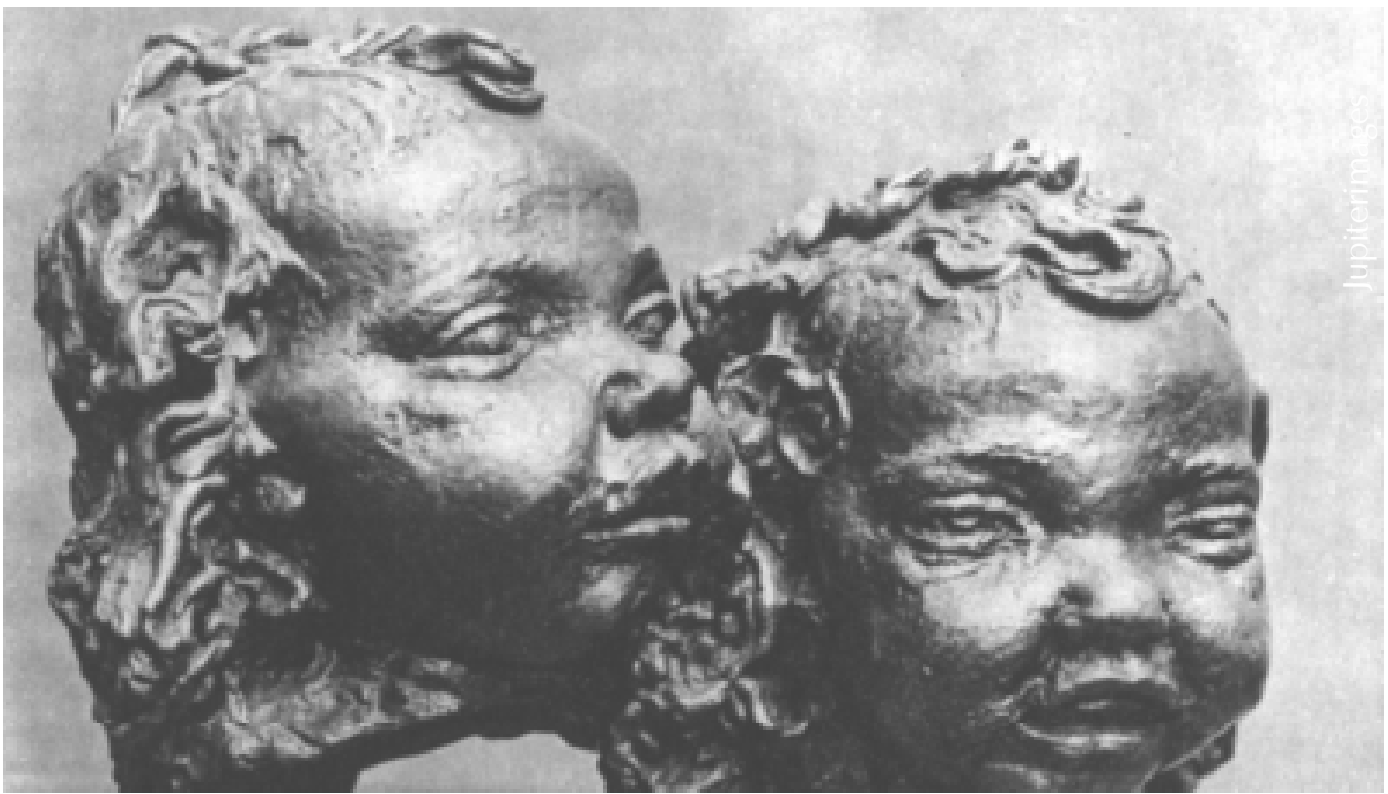

A atual legislação que norteia a prática jurídica em torno da questão da criança e do adolescente é fruto de um longo processo de construção dos direitos humanos, que inaugurou, a partir da Declaração Universal dos Direitos da Criança, em 1959, a filosófica Doutrina da Proteção Integral das Nações Unidas para a Infância. Isso significou uma mudança na concepção de criança, que passou a ser considerada sujeito de direito, merecedora de proteção especial em virtude do reconhecimento do seu estado peculiar de desenvolvimento. Em 1989, a Convenção Internacional sobre os Direitos da Criança consagrou tal Doutrina e forçou os países membros da ONU a formularem políticas próprias de defesa e garantia dos direitos da criança e do adolescente, o que fez, no Brasil, culminar na elaboração e aprovação do Estatuto da Criança e do Adolescente, Lei no 8.069/90. O que se observa, porém, no cenário atual, são várias e sérias violações desses direitos, tanto no âmbito das relações familiares quanto no âmbito das organizações institucionais. 
Os estudos a respeito da violência contra crianças e adolescentes têm revelado tratar-se de uma prática enraizada na história do nosso país desde a colonização e chegada dos jesuítas em nossa terra (Del Priore, 1999). Os estudos também têm-se proposto a avaliar e/ou compreender como se dá a intervenção do Estado quando constatada a violação dos direitos, e seus resultados têm apontado a dificuldade do poder judiciário em aplicar a lei quando se trata de violência de pais contra filhos, dentre outras razões, porque ainda subjaz às práticas jurídicas a concepção de que os pais podem exercer um poder (quase) ilimitado sobre a vida dos filhos (Rosa, 2003). Este artigo propõe uma reflexão acerca da noção do conceito de violência presente no Direito, bem como avaliar suas implicações éticas quando da aceitação de tal conceito. Para tal, recorreremos ao conceito de violência em Hannah Arendt e Marilena Chauí, pretendendo construir um pensamento sobre o qual a avaliação e a aplicação do conceito atual de violência serão realizadas.

\section{O Conceito de Violência em Hannah Arendt}

Em Sobre a Violência, Arendt (1994) distingue cinco palavras que, muitas vezes, costumamos usar como sinônimas: "poder", "vigor", "força", "autoridade" e "violência". "Poder", diz ela, "corresponde à habilidade humana não apenas para agir, mas para agir em concerto. O poder nunca é propriedade de um indivíduo; pertence a um grupo e permanece em existência apenas na medida em que o grupo se conserva unido" (p. 36). O "vigor", enquanto entidade individual, é definido como "a propriedade inerente a um objeto ou pessoa e pertence ao seu caráter, podendo provar-se a si mesmo na relação com outras coisas ou pessoas, mas sendo essencialmente diferente delas" (p. 37). Já "força", termo destacado pela autora como o sinônimo de "violência" mais utilizado no discurso cotidiano, "deveria ser reservado, na linguagem terminológica, às 'forças da natureza' ou 'à força das circunstâncias' isto é, deveria indicar a energia liberada por movimentos físicos ou sociais" (p. 37). A "autoridade" pode ser investida em pessoas ou postos hierárquicos, e "sua insígnia é o reconhecimento inquestionável por aqueles a quem se pede que obedeçam; nem a coerção nem a persuasão são necessárias" (p. 37). Finalmente, a violência distingue-se de todos os demais termos pelo seu caráter instrumental, estando "próxima do vigor, posto que os implementos da violência, como todas as outras ferramentas, são planejados e usados com o propósito de multiplicar o vigor natural até que, em seu último estágio de desenvolvimento, possam substituí-lo" (p. 37).
Refletindo sobre a relação entre poder e violência, concluímos que, para Arendt, não é a violência que gera o poder, pelo contrário, ela aparece quando o poder está ameaçado: "poder e violência são opostos; onde um domina absolutamente, o outro está ausente" (Arendt, 1994, p. 44). Distinguindo "poder" de "violência", a filósofa alemã diz: "uma das mais óbvias distinções entre poder e violência é a de que o poder sempre depende dos números, enquanto a violência, até certo ponto, pode operar sem eles, porque se assenta em implementos" (p. 35). Ela ainda complementa: "A forma extrema do poder é o Todos contra Um, a forma extrema de violência é o Um contra Todos" (p. 35).

A violência pode ser justificada, mas nunca será legítima, diz Arendt. O poder sim, esse é legítimo, e a mais simples forma de legitimação é o voto. A violência pode ser justificada porque traz queixas à atenção pública (conforme Arendt, 1994). Denuncia uma ausência de diálogo e, em última instância, reclama a falta de cidadania. A burocratização da vida pública implica uma atração pela violência, pois, em uma burocracia plenamente desenvolvida, não há ninguém a quem se possa inquirir, a quem se possa apresentar queixas, sobre quem exercer as pressões do poder: "A burocracia é a forma de governo na qual todas as pessoas estão privadas da liberdade política, do poder de agir, pois o domínio de Ninguém não é um não-domínio, e, onde todos são igualmente impotentes, temos uma tirania sem tirano" (p. 59). A "violência", na concepção arendtiana, não se basta a si, ela sozinha não leva a nada. Por ser de natureza instrumental, necessita de justificativa, mas "sua justificação perde em plausividade quanto mais o fim almejado se distancia no futuro. Ninguém questiona o uso da violência em defesa própria porque o perigo é não apenas claro, mas também presente, e o fim que justifica os meios é imediato" (Arendt, 1994, p. 41.)

Assim, uma das justificativas para a violência, conforme Arendt (1994), dá-se quando ela é utilizada em legítima defesa. A violência é justificada quando constitui uma ameaça ao corpo político ou "na geração do poder político, ou fundação de um novo corpo político, manifestado sobretudo nos atos de guerra e de revolução" (Santos, 1998, p. 29), ou seja, na destruição de velhos poderes, objetivando a instituição de novos.

Para Arendt, a violência é um fenômeno cultural que advém da tentativa de arrancar as máscaras da hipocrisia e da mentira, e da consciência de uma injustiça praticada (Santos, 1998, p. 28).

Dessa forma, "a violência teria um papel retórico a desempenhar, dramatizando queixas e trazendo- 
as à atenção pública, visando a alcançar objetivos a curto prazo e, assim, operar reformas em uma ordem política dada" (Santos, 1998, p. 29). Quanto menor a liberdade (entendida na visão arendtiana como participação nas coisas públicas ou admissão ao mundo político), mais queixas necessitam ocupar a esfera pública.

\section{A Violência no Brasil: um Mascaramento Necessário}

Na sociedade brasileira, o caráter emancipatório da violência que é destacado por Arendt não é visualizado, porque

"o exercício da violência externa e concretamente visual é, não raro, estimulado ou destacado diurnamente, precisamente para banalizá-la e, com isso, embargar ou bloquear o pensamento analítico e o discurso crítico a respeito das bases sociais e difusas onde deitam as verdadeiras raízes da violência externa (Alves, 1998, p. 251-253)."

A prática do Direito tem exercido também essa função de banalizar a violência. Os estudos a respeito do sistema judiciário têm conseguido desvelar as artimanhas que tal sistema possui para impedir uma atitude crítica diante da violência. Um dos estudos realizados por Adorno (1996) compõe o universo desses trabalhos. Analisando o tratamento dispensado a réus brancos e negros, o autor constatou haver claras evidências de discriminação racial na Justiça brasileira. Dentre outros fatos, sua pesquisa revelou que "réus negros tendem a ser mais perseguidos pela vigilância policial; (...) experimentam maiores obstáculos de acesso à justiça criminal e maiores dificuldades de usufruírem do direito de ampla defesa" (Adorno, 1996, p. 272). Isso ajuda a manter o estereótipo de que os negros são mais propensos a cometerem crimes por constituírem a maior parte da população carcerária no Brasil.

A análise de processos jurídicos a respeito da violência contra crianças, realizada por Rosa (2003), permitiu verificar o uso de argumentos por parte dos juizes que desqualificam os atos de violência de pais contra filhos. Os resultados apontam que o discurso jurídico a respeito dos maus tratos contra crianças é composto, em sua maior parte, de um raciocínio falacioso pautado em crenças e valores que legitimam a opressão e o poder dos pais, disfarçando o verdadeiro sentido da violência.

Essa produção de sentidos a respeito da violência em nossa sociedade não acontece de forma desarticulada. Chauí (1999) apresenta os dispositivos responsáveis para que a violência real fique oculta; são eles:
1- um dispositivo jurídico, que localiza a violência apenas no crime contra a propriedade e contra a vida; 2) um dispositivo sociológico, que considera a violência um momento de anomia social, isto é, como um momento no qual grupos sociais 'atrasados' ou 'arcaicos' entram em contato com grupos 'modernos', e 'desadaptados; 3) um dispositivo de exclusão, isto é, a distinção entre um 'nós brasileiros não-violentos' e um 'eles violentos'; 4) um dispositivo de distinção entre o essencial e o acidental: por essência, a sociedade brasileira não seria violenta, e, portanto, a violência é apenas um acidente na superfície social sem tocar em seu fundo essencial não-violento (...) (p. 3).

Devido a esse último dispositivo, comenta Chauí (1999), os meios de comunicação costumam referir-se à violência com as palavras "surto", "onda", "epidemia", "crise", ou seja, termos que indicam um fenômeno anômalo, passageiro e acidental.

"Dessa forma, as desigualdades econômicas, sociais e culturais, as exclusões econômicas, políticas e sociais, o autoritarismo que regula as relações sociais, a corrupção como forma de funcionamento das instituições, o racismo, o sexismo, as intolerâncias religiosa, sexual e política não são consideradas formas de violência, isto é, a sociedade brasileira não é percebida como estruturalmente violenta, e, por isso, a violência aparece como um fato esporádico superável (Chauí, 1999, p. 3)."

Nesse contexto, e para que se entenda a real dimensão da violência doméstica, queremos ressaltar a definição de violência como

1- tudo o que age usando a força para ir contra a natureza de algum ser (é desnaturar); 2) todo ato de força contra a espontaneidade, a vontade e a liberdade de alguém (é coagir, constranger, torturar, brutalizar); 3) todo ato de violação da natureza de alguém ou de alguma coisa valorizada positivamente por uma sociedade (é violar); 4) todo ato de transgressão contra o que alguém ou uma sociedade define como justo e como um direito (Chauí, 1999, p. 3).

Acatando essa definição dada por Chauí, ampliase o entendimento sobre a violência e a magnitude desse fenômeno em nossa sociedade, mas, grosso modo, a violência é entendida como aquilo que "constitui-se na intervenção física de um indivíduo ou grupo contra outro indivíduo ou grupo..." (Alves, 1998, p. 247), com o agravante de que se "pressupõe, em tese, que a intervenção seja voluntária ou intencional por parte do agente que a exerce, apesar da emotividade que pode acompanhá-la". Sabemos, porém, que o Direito 
prescreve outras modalidades de violência; muitas, contudo, não têm sequer padrões sob os quais os exames postos à disposição pela ciência possam constituir provas, como, por exemplo, a violência psicológica.

\section{Violência, Ética e Direito}

Analisando comparativamente os dois modelos descritos de conceituação da violência, vemos que, no primeiro, elaborado por Chauí, a Ética distingue-se completamente da violência, enquanto no segundo, elaborado por Alves, a violência tem uma dimensão ética porque "a intenção de praticar o ato é condição necessária da violência" (Alves, 1998, p. 247).

Chauí (1999), defendendo a natureza distinta da Ética, argumenta que pensar em uma solução para a violência como um "retorno à Ética" significa pressupor que esta seja um elemento que, estando sempre pronto e disponível em algum lugar, pode ser perdido ou recolhido periodicamente. Esse enfoque da Ética tem três sentidos principais:

"aparece, primeiro, como reforma dos costumes e restauração de valores passados, e não como análise das condições presentes de uma ação ética (...) a seguir, surge como multiplicidade de 'éticas' (ética política, ética familiar, ética escolar, ética de cada categoria profissional, ética do futebol, ética da empresa), portanto, desprovida de qualquer universalidade e entendida como competência específica de especialistas (as comissões de ética). (...) A esses dois sentidos, acrescenta-se um terceiro, no qual a Ética é entendida como defesa humanitária dos direitos humanos contra a violência, isto é, tanto como comentário indignado contra a política, a ciência, a técnica, a mídia, a polícia e o Exército, quanto como atendimento médico-alimentar e militar dos deserdados da terra (p. 3)."

Sustentando-se por um tal discurso, a solução para a violência é remetida para as relações interpessoais que, fazendo uma escolha por serem éticas, podem ser capazes de não estabelecer-se pela violência. Sendo assim, a Ética "não só se confunde com a compaixão como ainda permanece cega às condições materiais da sociedade contemporânea" (Chauí, 1999, p. 3). Isso implica reconhecer que o fim da violência não será possível pela atuação individual de cada pessoa mas, antes, pela reformulação ou reconhecimento dos valores que sustentam a nossa sociedade. Isso faz com que a noção de violência seja esclarecida e reconhecida em nosso meio, ou seja, o que devo considerar como violência ou não. Chauí (2000) defende que só quando uma cultura e uma sociedade definem o que entendem por mal, crime e vício, circunscrevem aquilo que julgam violência contra um indivíduo ou contra um grupo; em conseqüência, erguem os valores positivos como barreiras éticas contra a violência.

Dessa forma, Chauí condena a concepção de "retorno à Ética" como alternativa de solução para a violência por ser uma "ideologia duplamente perversa", porque, "em vez de a ação reunir os seres humanos em torno de idéias e práticas positivas de liberdade e felicidade, ela os reúne pelo consenso sobre o mal" (p. 3).

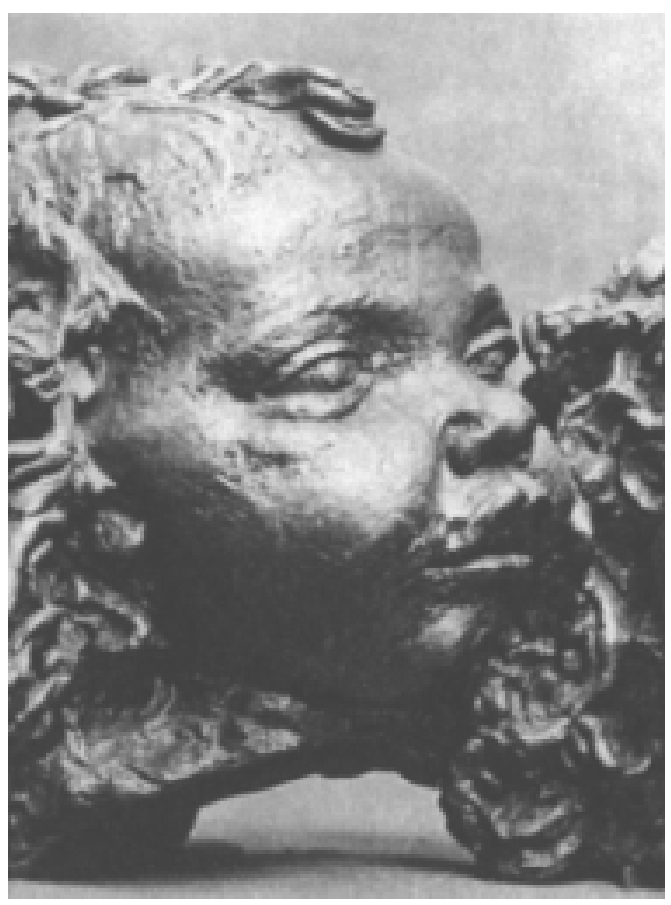

"...defendendo a natureza distinta da Ética, argumenta que pensar em uma solução para a violência como um "retorno à Ética" significa pressupor que esta seja um elemento que, estando sempre pronto e disponível em algum lugar, pode ser perdido ou recolhido periodicamente."

Uma outra conseqüência da conceituação apresentada por Alves (1998) é que ela desqualifica algumas ações da própria violência, dada a associação, quando do seu julgamento, à intenção de quem a pratica. "A intervenção física, na qual a violência consiste de forma inequívoca", afirma o mesmo autor, "tem por finalidade coagir, para destruir, ofender e causar dano a si mesmo ou a outrem. Se a intervenção física não tiver como fim essa ofensa, destruição ou dano, não se pode considerá-la como violência" (Alves, 1998, p. 248). Tal concessão à pratica da violência invalida outra característica legal da tipificação da violência: quando a intervenção é exercida contra a vontade da vítima. Isso acontece, por exemplo, quando há uma ação médica emergencial. "Nessa hipótese, pode-se exercer uma intervenção física sem o consentimento do paciente, e essa ação não é considerada uma violência. Não o é porque não se tem em mira o prejuízo, a tortura ou a destruição, mas, pelo contrário, a cura, o bem, o salvamento" (Alves, 1998, p. 242). 
De certa forma, essa concepção de violência está presente nos discursos a respeito da violência doméstica tanto dos sujeitos que praticam os atos de violência contra os filhos como dos que sofrem a violência, além de também estar presente no discurso daqueles que julgam esses atos em nossa sociedade. O argumento utilizado pelos pais, ao justificarem a prática de castigos aplicados aos filhos, sustenta-se pela idéia, ainda presente entre nós, de que os pais podem e devem exercer o poder de educação para o "bem dos filhos" independentemente dos limites estabelecidos pela lei. No discurso jurídico, também esse é o argumento mais freqüente na emissão das sentenças daqueles casos que chegaram a tal instância. Ao argumentarem a respeito dos fatos, os juízes ancoram seus argumentos nas considerações do contexto em que "tapas, chutes, socos e queimaduras" estiveram presentes na relação pais e filhos. Dessa forma, eles produzem um discurso capaz de desqualificar a violência, adotando como premissa principal o caráter educativo de tais atos (Rosa, 2003). Isso sugere "a possibilidade de se exercer uma violência não condenável, uma violência exercida de modo "justo" (Alves, 1998, p. 249).

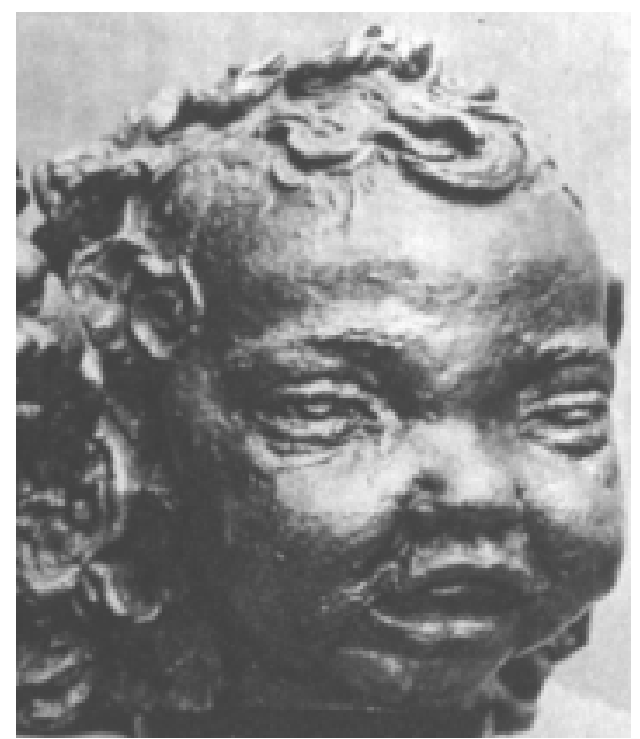

Um dos motivos pelo qual esse argumento jurídico encontra sustentação, como nos apontou Chauí (1999), é que, no Brasil, os crimes contra a pessoa, nos quais estão incluídos os crimes de maus tratos contra crianças e adolescentes, não são punidos porque não ferem os princípios da propriedade privada nos quais estão pautados a sociedade capitalista.

Outro motivo é a necessidade da manutenção da família tal como se apresenta no contexto atual.
Ao exercer o papel de socialização dos seus membros, a família reproduz as relações de poder presentes na sociedade, nas quais há dominantes e dominados. Assim, a família cumpre sua função de agente da reprodução ideológica que legitima o poder social, principalmente por ser o local da estruturação da vida psíquica. Como nos afirma Reis (1989), "é a maneira peculiar pela qual a família organiza a vida emocional de seus membros que Ihe permite transformar a ideologia dominante em uma visão de mundo, em um código de condutas e de valores que serão assumidos mais tarde pelos indivíduos" ( p. 104).

\section{À Guisa de Conclusão}

Baseando-nos nas proposições de Arendt, podemos dizer que a violência doméstica, aquela praticada por pais, parentes ou responsáveis pela criança ou adolescente, quase sempre ocorrida nos âmbitos da casa, não é uma prática justificável, porque não se enquadra em nenhuma das possibilidades apresentadas pela autora. Podemos, então, afirmar que toda explicação cujo intento seja justificar a violência doméstica não passa de um mascaramento de seus verdadeiros objetivos, encobrindo a real possibilidade de sua extinção.

A violência doméstica pode, contudo, ser considerada legítima em algum contexto? De acordo com a perspectiva arendtiana, sim, porque a legitimação é fruto do consenso da população: se, ao longo do tempo, a prática disciplinar caracterizada por castigos físicos foi adotada sem restrição na relação adulto e criança, então podemos concluir que ela foi legitimada. Sendo legitimada, ela constituiu um poder sustentado em manifestações de apoio popular. Tal como declara o velho adágio, "todo poder emana do povo".

Ao não reconhecer a violência contida nos atos de disciplinamento corporal contra crianças, o poder judiciário reforça o papel da família na manutenção da ordem social, ao mesmo tempo em que a utiliza para ocultar a força repressora que é derivada das próprias leis, em nossa sociedade.

Dessa forma, podemos concluir que a aplicação do Direito, tal como está fundamentada quanto ao que caracteriza um ato violento, não consegue abarcar situações como a violência doméstica, muito menos situações de violência institucionalizada. Não obstante, essas duas categorias de violência devem manter uma estreita relação, uma vez que estão à margem dos possíveis enquadramentos legais quanto aos danos que vêm causando. Além disso, ambas são necessárias para manter ostatus quo na medida em que reproduzem relações interpessoais reificadas. 
Edinete Maria Rosa \& Eda Terezinha de Oliveira Tassara Rua Dr. Eurico de Aguiar, 120/620, Praia do Canto, Vitória, ES. Cep. 29055280. E-mail: edineter@cchn.ufes.br

ADORNO, S. Violência e Racismo: Discriminação no Acesso à Justiça Penal. In Schwarez, L.M. e Silva, R. da. Raça e Diversidade. São Paulo: EDUSP, 1996

ALVES, A. C. A Violência Oculta na Violência Visível: a Erosão da Lei numa Ordem Injusta. In Pinheiro, P.S. (org.). São Paulo sem Medo: um Diagnóstico da Violência Urbana. Rio de Janeiro: Garamond, 1998.

ARENDT, H. Sobre a Violência. Rio de Janeiro: Relume-Dumará, 1994.

CHAUÍ, M. Uma Ideologia Perversa. Folha de São Paulo, São Paulo, Caderno Mais!, p. 3, 1999, 14 de março.

CHAUÍ, M. Convite à Filosofia. 12 ed. São Paulo: Ática, 2000

DEL PRIORE, M.L. M. (org.). História das Crianças no Brasil. São Paulo: Contexto, 1999.
SANTOS, S. G. B. O Conceito de Violência em Hannah Arendt: a Busca por um Lugar no Mundo. 1998. Dissertação de Mestrado em Filosofia) - Programa de Pós-Graduação em Filosofia, Universidade de São Paulo, São Paulo, 1998.

REIS, J. R. T.. Família, Emoção e Ideologia. In Lane, S. T. M. e Codo, W. (orgs.). Psicologia Social: o Homem em Movimento. 7 ed. Sáo Paulo: Brasiliense, 1989.

ROSA, E.M. Radiografia de um Processo Social: um Estudo Sobre a Relação Entre Direito, Família, Violência e Crianças. 2003. Tese de Doutorado em Psicologia - Programa de Pós-Graduação em Psicologia Social e do Trabalho, Universidade de São Paulo, São Paulo, 2003. 